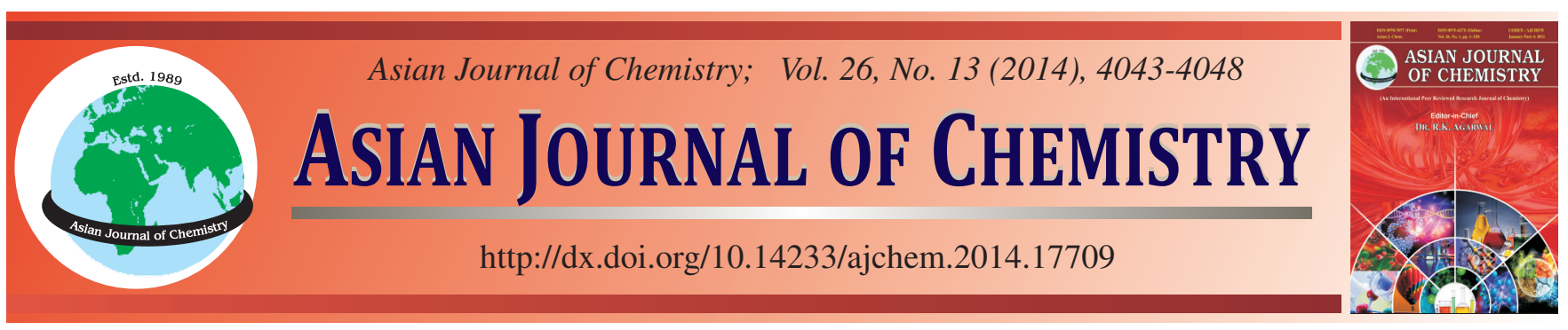

\title{
Analysis on Long-Term Emission and Reduction Potential of Greenhouse Gases in the Industrial Sector of Seosan City of Korea Using Long-Range Energy Alternatives Planning Model $\dagger$
}

\author{
Jindo CHUNG ${ }^{1, *}$ and SANGwOOK YoON ${ }^{2}$
}

${ }^{1}$ Department of Environmental Engineering, Hoseo University, Asan city, Chung-nam 336-795, Republic of Korea

${ }^{2}$ Graduate School, Department of Semiconductor and Display Engineering, Hoseo University, Asan city, Chung-nam 336-795, Republic of Korea

*Corresponding author: E-mail: jdchung@ hoseo.edu

\begin{abstract}
In this study, greenhouse gases emissions and reduction potentials were predicted using the long-range energy alternatives planning model mainly for industrial sector in Korea's Seosan city that has a large consumption structure of energy. Energy consumption and greenhouse gases emissions were also predicted through the analysis of four scenarios resulting from the application of the reduction effect according to the basic energy plan and technology options of petrochemical industries. In scenario I, the policy of the national basic energy plan was analyzed which showed an improvement of energy basic by an annual average of $2.6 \%$ until 2030. Scenario I showed the effect of reducing greenhouse gases emissions of $18.23 \%, 297.2$ thousand $\mathrm{tCO}_{2}$; scenario II, about $14 \%$ in 2030 over 2005 . It was analyzed that scenario III showed a reduction of $8 \%, 135$ thousand $\mathrm{tCO}_{2}$ compared to the baseline scenario; scenario IV showed a reduction of about $0.2 \%$ in greenhouse gases emissions. Accordingly, based on the result of the $0.75 \%$ scenario which is commonly used as the annual average efficiency improvement rate of energy, the $30 \%$ reduction of greenhouse gases emissions was analyzed to be a difficult goal until 2020, the baseline of the response measures to climate change of Seosan city compared to 2005 emissions.
\end{abstract}

Keywords: Greenhouse gases, Climate change, Long-range energy alternatives planning model, $\mathrm{CO}_{2}$ gas.

\section{INTRODUCTION}

Korea's average temperature has risen $1.7^{\circ} \mathrm{C}$ over the past 100 years, which is more than twice the Earth's average temperature gains $\left(0.74^{\circ} \mathrm{C}\right)$ and the annual average temperature increase also shows around two times the average. Especially, the temperature rise has continuously been accelerated and it has turned out that more than $90 \%$ of the increase in the greenhouse gases (GHGs) in the atmosphere that cause global warming was caused by human activities. This globally most concerned matter of issue of climate change due to greenhouse gases requires the participation of the entire world, rather than one individual or country; so every country around the world is paying efforts for mutual cooperation.

As part of these efforts, the 'Kyoto Protocol' was adopted in the Third Conference of the Parties in1997, which specifically stated the targets and implementation measures for the developed countries to reduce greenhouse gases emissions ${ }^{1-3}$. In the 13th Conference of the Parties held in 2007, in addition to the formulation of additional reduction goal and implementation plan of the reduction commitments by developed countries, the 'Bali Road Map' was adopted that requires the developing countries to do domestic reduction actions for the sustainable development through technical and financial support and the ability improvement ${ }^{4}$. Therefore, the participation pressure for developing countries to reduce greenhouse gases emissions is being strengthened since 2012. Though they failed to reach an agreement in the form of General Assembly Decision (COP decision) at the 15th Conference of the Parties, which was held in December 2009, due to the difference between the positions of developed and developing countries, but the Copenhagen agreement was adopted to serve as the basis of negotiations in the future, so the sluggish negotiations for a post-Kyoto system has gained momentum ${ }^{5,6}$.

Korea is not the mandatory reduction target country, but it ranks 7th among OECD countries emitting greenhouse gases including 590 million ton of $\mathrm{CO}_{2}$ gas in 2005 and has large energy consumption growth compared to developed countries, so it is classified as the most likely country among developing countries to which the obligation applies. The present Korea has been making a national effort in preparation for an obligation to reduce greenhouse gases emissions, so it is needed for local governments to respond to this effort through building greenhouse gases statistics and reduction efforts ${ }^{7}$. 
In this study, therefore, as Korea's greenhouse gases emission reduction obligations are likely to be involved in the postKyoto regime and role of local governments in greenhouse gases reduction activities is expected to increase, it is intended to analyzed the long-term greenhouse gases emissions and reduction potential utilizing the LEAP (long-range energy alternatives planning) model which is one of the 14 representative greenhouse gases reduction policy analysis models suggested by UNFCCC (United Nations Framework Convention on Climate Change), targeting Seosan city where a largescale petrochemical complex is located in Korea.

\section{EXPERIMENTAL}

Long-range energy alternatives planning model and analysis method: In this study, the long-range energy alternatives planning model ${ }^{8-10}$ was used for the analysis of longterm greenhouse gases emission reduction potential. Longrange energy alternatives planning model is currently being used in more than 150 countries, including the United States that developed this program and is one of the 14 reduction policy analysis model introduced by the UNFCCC Technology Information Clearing House. Using long-range energy alternatives planning model, prospects for the mid- and long-term greenhouse gases emissions and the analysis of reduction potential are easy. The gradual changes of the exogenous variables can be reflected in the model because it can describe socio-economic conditions, the form of economic subjects and technological changes using functions included in the timeseries wizard. In addition, the cost analysis capabilities are included to calculate the current value or annual value of the multi-period direct costs that occurred in the energy sector. It also has shortcomings however, that it has difficult to analyze the general equilibrium ripple effects or macroeconomic ripple effects.

The long-range energy alternatives planning model used in this study consists of Analysis view, Result view, technology environment DB (TED) and other minor screens. Analysis view is an essential part of model building to enter the technical and cost characteristics such as final energy consumption, conversion process and energy supply that construct the energy system. Result view is the output screen that displays the result on the completion of the input data from the Analysis view; displays the analysis results of major air pollution emissions including the consumption and supply of energy, imports and exports and greenhouse gases. Technology environment DB is the summarized DB form of energy related to technical, environmental and cost characteristics; it consists of the coefficient of the IPCC's greenhouse gases emissions and characteristic values of major technology which were entered by the DB developers; users can also add technologies or attributes in it.

A precaution to take advantage of the long-range energy alternatives planning model is that the quality of the input data has a huge impact on the results like other models. Therefore, to take the most of an advantage of the long-range energy alternatives planning model for the effective greenhouse gases emission reduction potential analysis, it can be said that building the basis of the input data is the most important.

\section{RESULTS AND DISCUSSION}

\section{Baseline scenario analysis}

Prediction of added-value and importance in the industrial sector: Energy consumption in the industrial sector has different aspects by the industry but also has one thing in common in terms that it is proportional to the level of production. Therefore, the added-value estimated by the industrial structure and the activities of the industrial sector are shown in Table-1. Added-value of the industrial sector of Seosan city was predicted to increase from \$2696.24 million in 2005 to \$ 3014.64 million in 2030. By industrial sector, the proportion of agriculture and forestry is expected to decrease gradually and the mining sector will be maintained without change and importance of the manufacturing and construction industries is expected to increase. Braking down the most added-value manufacturing sector by industry, the proportion of the petrochemical industry rose from $66.43 \%$ in 2005 to $67.70 \%$ in 2030 and the proportion of all sectors except for the petrochemical industry was predicted to reduce.

\begin{tabular}{ccccc}
\multicolumn{5}{c}{ TABLE-1 } \\
ADDED-VALUE ESTIMATED BY THE \\
INDUSTRIAL STRUCTURE AND THE ACTIVITIES \\
OF THE INDUSTRIAL SECTORS: UNIT US\$ \\
\hline Items & 2005 & 2013 & 2020 & 2030 \\
\hline Agriculture & 270.56 & 272.47 & 274.12 & 276.04 \\
Forestry & $10.03 \%$ & $9.70 \%$ & $9.43 \%$ & $9.15 \%$ \\
Fisheries & 9.26 & 9.26 & 9.26 & 9.26 \\
\hline \multirow{2}{*}{ Mining } & $0.34 \%$ & $0.33 \%$ & $0.32 \%$ & $0.31 \%$ \\
\hline \multirow{2}{*}{ Manufacture } & $2,101.2$ & $2,192.6$ & $2,268.47$ & $2,354.33$ \\
& $77.93 \%$ & $78.04 \%$ & $78.08 \%$ & $78.10 \%$ \\
\hline \multirow{2}{*}{ Construction } & 315.22 & 335.27 & 353.48 & 375.01 \\
& $11.7 \%$ & $11.93 \%$ & $12.17 \%$ & $12.44 \%$ \\
\hline \multirow{2}{*}{ Total } & $2,696.24$ & $2,809.6$ & $2,905.33$ & $3,014.64$ \\
& $100 \%$ & $100 \%$ & $100 \%$ & $100 \%$ \\
\hline
\end{tabular}

Seosan city's industrial sector energy consumption in 2005 accounted for 813 thousand TOE, 1/3 of the Seosan city's full energy consumption. Table- 2 shows the energy consumption according to the energy sources by sector in the base year. The total energy consumption of the industrial sector was 812.74 thousand TOE as the base year, consisting $54 \%$ of the consumption of electricity and petroleum products and $46 \%$ of petroleum products. The city-gas consumption was to examine from 2003 until 2009, which proves a continuous increase in its consumption. The cause of reason was analyzed to be the increase in the production of the petrochemical industry which accounts for the largest portion of Seosan city's industrial sector and the increase of the Seosan city population. In addition, the analysis of energy consumption by energy sources according to the manufacturing sector shows that the petrochemical sector accounted for $81 \%$ and transport accounted for $15 \%$ of the total energy consumption of 637.56 thousand TOE in the manufacturing sector.

Prediction of energy consumption baseline: Long-range energy alternatives planning model was built energy consumption status of Seosan city's industrial sector based on addedvalue prediction analyzed previously and the Business As 


\begin{tabular}{|c|c|c|c|c|c|c|}
\hline \multicolumn{7}{|c|}{$\begin{array}{c}\text { TABLE-2 } \\
\text { CONSUMPTION OF INDUSTRIAL SECTOR AS ENERGY S }\end{array}$} \\
\hline \multicolumn{2}{|c|}{ Index } & Total & Agriculture & Mining & Manufacture & Construction \\
\hline \multicolumn{2}{|c|}{ Total } & 812.74 & 25.5 & 5.86 & 637.56 & 143.82 \\
\hline \multirow{10}{*}{ Petroleum } & Gasoline & 5.05 & 1.65 & - & 3.40 & - \\
\hline & Kerosene & 5.95 & 1.35 & - & 4.60 & - \\
\hline & Diesel & 53.39 & 9.65 & - & 40.86 & 2.88 \\
\hline & Crude oil & 1.94 & - & - & 0.50 & 1.44 \\
\hline & Heavy oil & - & - & - & - & - \\
\hline & Bunker C oil & 111.79 & 0.60 & - & 111.19 & - \\
\hline & Propane & 151.01 & 0.15 & - & 11.36 & 139.50 \\
\hline & Butane & 45.25 & - & - & 45.25 & - \\
\hline & Extra oil & 0.14 & - & 0.14 & - & - \\
\hline & Subtotal & 374.38 & 13.40 & - & 217.16 & 143.82 \\
\hline \multirow{2}{*}{\multicolumn{2}{|c|}{$\begin{array}{l}\text { LNG } \\
\text { Electricity }\end{array}$}} & 31.5 & - & - & 31.50 & - \\
\hline & & 406.72 & 12.10 & 5.72 & 388.90 & - \\
\hline
\end{tabular}

Usual (BAU) was analyzed to prospect energy consumption and greenhouse gases emissions until 2030. Table-3 provides the results of the outlook of energy consumption by the industrial sector. As a result, the energy consumption in the industrial sector appeared to increase by approximately $66 \%$ from 812.74 thousand TOE in 2005 to 1352.91 thousand TOE in 2030. Analysis of the energy consumption prospect for each sector showed an increase in all sectors except mining during the entire predict period, which is due to the energy consumption in accordance with the increase of value-added. However, the major reason for reduced energy consumption despite no change of value added in mining was analyzed to be the reduction of the number of workers.

TABLE-3

OUTLOOK OF ENERGY CONSUMPTION BY THE INDUSTRIAL SECTORS (2005-2030); UNIT: THOUSAND TOE

\begin{tabular}{ccccc}
\hline Items & 2005 & 2013 & 2020 & 2030 \\
\hline Agriculture & 25.5 & 28 & 30.2 & 30.1 \\
Forestry & $3.14 \%$ & $2.89 \%$ & $2.73 \%$ & $2.22 \%$ \\
Fisheries & & & & \\
Mining & 5.9 & 5.7 & 5.6 & 5.1 \\
& $0.72 \%$ & $0.59 \%$ & $0.51 \%$ & $0.38 \%$ \\
Manufacture & 637.6 & 772.4 & 890.4 & $1,091.6$ \\
& $78.45 \%$ & $79.65 \%$ & $80.42 \%$ & $80.66 \%$ \\
Construction & 143.8 & 163.6 & 180.9 & 226.5 \\
& $17.69 \%$ & $16.87 \%$ & $16.34 \%$ & $16.74 \%$ \\
Total & 812.7 & 969.7 & $1,107.1$ & $1,353.3$ \\
& $100 \%$ & $100 \%$ & $100 \%$ & $100 \%$ \\
\hline
\end{tabular}

As a result of the energy consumption outlook by the manufacturing sector to analyze the factors of the increasing trend for the manufacturing sector with the biggest energy consumption, the petrochemical sector energy consumption shows an increase rate of $0.87 \%$ from 517.5 thousand TOE in 2005 to 642 thousand TOE in 2030 owing to the ongoing foster of the petrochemical industry and a decline in the industries such as food, fiber, wood, ceramics and steel industry.

Prediction of greenhouse gases emission: Baseline greenhouse gases emissions were evaluated on the basis of the predicted energy consumption previously. Table- 4 is the result of the calculated greenhouse gases emissions of the industrial sector in the baseline scenario. The industrial sector's greenhouse gases emissions were expected to increase by $24 \%$ annually in average from 1,215 thousand ton of $\mathrm{CO}_{2} \mathrm{eq}$ in 2005
TABLE-4

GHGS EMISSION OF INDUSTRIAL SECTOR IN THE BASELINE SCENARIOS (BAU, 2005-2030); UNIT: THOUSAND tCO $_{2}$ eq

\begin{tabular}{cccccc}
\hline Items & 2005 & 2013 & 2020 & 2030 & $05-30$ rate \\
\hline Agriculture & 41 & 43 & 46 & 49 & $0.70 \%$ \\
Forest, fishery & & & & & \\
Mining & - & - & - & - & - \\
Manufacture & 735 & 717 & 701 & 771 & $0.19 \%$ \\
Construction & 438 & 499 & 551 & 690 & $1.83 \%$ \\
Total & 1,215 & 1,259 & 1,298 & 1,510 & $0.87 \%$ \\
\hline
\end{tabular}

to 1,510 thousand ton of $\mathrm{CO}_{2} \mathrm{eq}$ in 2030. Among the industrial sectors, manufacturing sector accounts for the most greenhouse gases emissions of $56 \%$. Therefore, the manufacturing sector among the industrial sectors needs to be prioritized in establishing climate change countermeasures. In addition, prospecting the greenhouse gases emissions by the manufacturing sector in the baseline scenario, the greenhouse gases emissions that are produced in the petrochemical industry accounted for $89.95 \%$ of the greenhouse gases emitted in the entire manufacturing. This is a unique feature of Seosan city, which is considered to need measures to manage focused on the petrochemical industry in the industrial sector when establishing measures to respond to climate change of Seosan city.

Analysis of greenhouse gases reduction potentials as the scenario: The effect of greenhouse gases reduction was analyzed by energy-related plan based on the previously predict energy consumption and consequent greenhouse gases emissions in the industrial sector of Seosan city. There are four scenarios used in the analysis to reduce greenhouse gases emissions when introducing reductions policies.

Scenario I: Application of national basic energy plan: In this research study, the range is limited to Seosan city, but the regional energy plan cannot be prepared regardless of the national energy plan. Thus, in Scenario I, the 'National basic energy plan' presented by the government of Korea was used to estimate energy consumption and greenhouse gases reduction potential. National basic energy plan ${ }^{11}$, as a top-level plan on energy sector to provide energy principle and direction, presents the improvement of energy basic unit for the transition to the low consumption society. An annual average improvement of $2.6 \%$ was set as a goal from 0.347 in 2006 to the level of 0.185 in 2030 . 
The scenario applied with the manufacturing sector that has the highest proportion of energy consumption and greenhouse gases emissions is as Table-5. Assuming the energy basic unit of the manufacturing sector to have a $2.6 \%$ improvement, Seosan city manufacturing sector's energy consumption in 2030 was expected to reach 891.3 thousand TOE, accomplishing the reduction of 507.3 thousand TOE compared to the baseline scenario.

\section{TABLE-5}

TOE REDUCTION POTENTIALS IN INDUSTRIAL SECTORS (SCENARIO I, 2005-2030); UNIT: THOUSAND TOE

\begin{tabular}{ccccc}
\hline & 2005 & 2013 & 2020 & 2030 \\
\hline BAU & 812.6 & 969.6 & $1,107.0$ & $1,398.6$ \\
$\begin{array}{c}\text { Scenario I (intensity } \\
\text { 2.6 \%) }\end{array}$ & 812.6 & 835.9 & 856.3 & 891.3 \\
Efficiency & 0.0 & -133.7 & -250.7 & -507.3 \\
\hline
\end{tabular}

Table- 6 shows the analysis of the effects of greenhouse gases emissions according to $2.6 \%$ improvement of energy basic unit. The effect of reduction of greenhouse gases emissions through $2.6 \%$ improvement of energy basic unit of the manufacturing sector has shown 1,332 thousand $\mathrm{tCO}_{2}$ greenhouse gases reduction in 2030, $18.23 \%$ compared to the baseline scenario.

TABLE-6

GHGS REDUCTION POTENTIALS IN INDUSTRIAL SECTORS (SCENARIO I, 2005-2030); UNIT: THOUSAND $\mathrm{tCO}_{2}$ eq

\begin{tabular}{ccccc}
\hline & 2005 & 2013 & 2020 & 2030 \\
\hline BAU & $1,214.4$ & $1,259.0$ & $1,298.0$ & $1,629$. \\
Scenario I & $1,214.4$ & $1,249.3$ & $1,279.8$ & 1,332 \\
(intensity 2.6 \%) & & & & \\
Efficiency & - & -9.7 & -18.2 & -297.2 \\
\hline
\end{tabular}

Scenario II: Autonomous energy efficiency improvement (AEEI): Scenario II has used the autonomous energy efficiency improvement that is being used by some of the topdown models. Some top-down models have utilized the assumption that the energy efficiency owing to exogenous technological change typically increases at annual average $0.75 \%$.

Some top-down models have utilized the assumption that the energy efficiency owing to exogenous technological change typically increases at annual average $0.75 \%$. Thus, the analysis in scenario II was performed on the energy consumption and greenhouse gases reduction potentials in the manufacturing sector through improvement of the energy basic unit according to the exogenous technological change. Table-7 shows the result TOE reduction potentials in industrial sectors. If the energy basic unit of the manufacturing sector is improved by $0.75 \%$, the energy consumption in the industrial sector of Seosan city will be 1,070 thousand TOE as of 2030. It was analyzed to bring the reduction of 328.9 thousand TOE in the energy consumption compared to the base scenario, BAU.

The reduction effect of greenhouse gases emissions through improved energy basic unit by $0.75 \%$ is as Table- 8 . The reduction effect of greenhouse gases emissions through $0.75 \%$ improvement of energy basic unit of the manufacturing sector is 1389.5 thousand $\mathrm{tCO}_{2}$ greenhouse gases in 2030, $14.71 \%$ compared to the baseline scenario, with the reduction of 239.7 thousand $\mathrm{tCO}_{2}$.
TABLE-7

TOE REDUCTION SCENARIO IN INDUSTRIAL SECTORS (SCENARIO II, 2005-2030); UNIT: THOUSAND TOE

\begin{tabular}{ccccc}
\hline & 2005 & 2013 & 2020 & 2030 \\
\hline BAU & 812.6 & 969.6 & 1,107 & $1,398.6$ \\
$\begin{array}{c}\text { Scenario II } \\
\text { (intensity }\end{array}$ & 812.6 & 866.7 & 914.1 & $1,069.7$ \\
$0.75 \%)$ & & & & \\
Efficiency & - & -102.9 & -192.9 & -328.9 \\
\hline
\end{tabular}

\begin{tabular}{|c|c|c|c|c|}
\hline \multicolumn{5}{|c|}{$\begin{array}{l}\text { TABLE-8 } \\
\text { GHGS REDUCTION SCENARIO IN INDUSTRIAL SECTORS } \\
\text { (SCENARIO II, 2005-2030); UNIT: THOUSAND } \text { tCO }_{2} \text { eq }\end{array}$} \\
\hline & 2005 & 2013 & 2020 & 2030 \\
\hline BAU & $1,214.4$ & 1,259 & 1,298 & $1,629.2$ \\
\hline $\begin{array}{c}\text { Scenario II } \\
\text { (intensity } 0.75 \% \text { ) }\end{array}$ & $1,214.4$ & $1,258.4$ & $1,296.8$ & $1,389.5$ \\
\hline Efficiency & - & -0.6 & -1.2 & -239.7 \\
\hline
\end{tabular}

Scenario III: Supply of high-efficiency motor: In Scenario III, the reduction effect of greenhouse gases was analyzed applying the findings of the IEA ${ }^{12,13}$ that the replacement of motors, which accounts for $60 \%$ of the power consumption, with high-efficiency motors, reduces the loss of energy by 20$25 \%$ than reference standard motors, increasing the efficiency of $10 \%$. According to the study of IEA, the replacement of motors, which accounts for $60 \%$ of the power consumption, with high-efficiency motors reduces the loss of energy by 20 $25 \%$ than reference standard motors, increasing the efficiency of $10 \%$. The penetration rate of the high-efficiency motors in Korea shows a gradual increase, being $10 \%$ as of 2005. The reason for the low penetration of high-efficiency motors is because their price that is 15-30\% more expensive compared to standard motors. Accordingly, the Ministry of Knowledge Economy and the Korea Energy Management Corporation have been supporting subsidies since 2002 to expand the supply of high-efficiency motors.

The analysis in Scenario III was performed on the energy consumption and greenhouse gases reduction potentials in case the energy consumption efficiency for the power in the industrial sector increases by $10 \%$ owing to supply of high-efficiency motors. Table 9 shows the result TOE reduction potentials in industrial sectors. The energy consumption in the manufacturing sector in 2030 according to the dissemination of highefficiency motors is 1,339 thousand TOE, a reduction of 59.4 thousand TOE compared to the baseline scenario.

\section{TABLE-9}

TOE REDUCTION SCENARIO IN INDUSTRIAL SECTORS (SCENARIO III, 2005-2030); UNIT: THOUSAND TOE

\begin{tabular}{ccccc}
\hline & 2005 & 2013 & 2020 & 2030 \\
\hline BAU & 812.6 & 969.6 & 1,107 & $1,398.6$ \\
Scenario III & 812.6 & 966.3 & $1,100.9$ & $1,339.2$ \\
(Intensity 0.75 \%) & & & & \\
Efficiency & - & -3.3 & -6.1 & -59.4 \\
\hline
\end{tabular}

The result shows Table-10 of greenhouse gases reduction potentials. The greenhouse gases reduction potentials is 135.1 thousand $\mathrm{tCO}_{2}$ by 2030 compared to baseline scenario. Since the high-efficiency motors can be applied only to power consumption factors, greenhouse gases emission reduction efficiency of in the entire manufacturing sectors was analyzed to be $8 \%$. 


\begin{tabular}{|c|c|c|c|c|}
\hline \multicolumn{5}{|c|}{$\begin{array}{c}\text { TABLE-10 } \\
\text { GHGS REDUCTION SCENARIO IN INDUSTRIAL SECTORS } \\
\text { (SCENARIO III, 2005-2030); UNIT: THOUSAND } \mathrm{tCO}_{2} \mathrm{eq}\end{array}$} \\
\hline & 2005 & 2013 & 2020 & 2030 \\
\hline BAU & 1214.4 & 1,259 & 1,298 & 1629.2 \\
\hline $\begin{array}{c}\text { Scenario III } \\
\text { (Intensity } 0.75 \%)\end{array}$ & $1,214.4$ & $12,55.2$ & $1,290.8$ & $1,494.1$ \\
\hline Efficiency & 0 & -3.8 & -7.2 & -135.1 \\
\hline
\end{tabular}

Scenario IV: Greenhouse gases reduction technology in petrochemical industry: In Scenario IV, the greenhouse gases reduction potential was analyzed for the technology option $^{14}$ that can be applied to the petrochemical industry that accounts for $90 \%$ of the energy consumption in the manufacturing industry of Seosan city.

Technology options of the petrochemical industry applied for the reduction of energy consumption and greenhouse gases emissions of petrochemical sector were analyzed as Table- 11 . In the result of the Scenario IV that applied petrochemical industry technology options, 5.2 thousand TOE of energy consumption can be reduced if the entire reduction options are applied. It was analyzed that the most efficient process among the technology options was butadiene (butadiene extractive distillation process using the new solvent) and the process that showed the lowest reduction efficiency was Dived Wall Calumn Technology (energy-saving technology using Dived Wall Calumn in the manufacturing process of benzene and toluene).

TABLE-11

TOE REDUCTION SCENARIO IN PETROCHEMICAL SECTOR (SCENARIO IV, 2005-2030); UNIT: THOUSAND TOE

\begin{tabular}{lcccc}
\hline & 2005 & 2013 & 2020 & 2030 \\
\hline Chemical and petro & 517.5 & 537.9 & 555.8 & 642 \\
Catalytic cracking & 517.5 & 537.3 & 554.6 & 640.7 \\
Methane cracking & 517.5 & 537.4 & 554.8 & 641.9 \\
Coking alloy & 517.5 & 537.8 & 555.6 & 639.9 \\
Metathesis & 517.5 & 537.4 & 554.8 & 640.4 \\
Dived wall calum & 517.5 & 537.4 & 554.8 & 641.9 \\
Butadien & 517.5 & 537.9 & 555.7 & 642 \\
Total & - & -2.2 & -4.5 & -5.2 \\
\hline
\end{tabular}

The analysis result of greenhouse gases reduction potentials by technology options is as Table-12. As the result of applying each technology option of the Scenario IV, it was estimated that the reduction effect of 10.1 thousand $\mathrm{tCO}_{2} \mathrm{eq}$ occurred in the petrochemical sector in 2030. The best process with the energy consumption reducing ability is the butadiene, but process with the best greenhouse gases reduction efficiency was analyzed to be catalytic cracking (ethylene production technology through naphtha cracking). The reason is considered to be the assumption that more than $98 \%$ of recoveries can be obtained in catalytic cracking process when $99.8 \%$ ethylene is produced from $80 \%$ ethylene mixture using the clay as a substrate to enhance selectivity and adsorption capacity ${ }^{15}$. In order to increase the reduction potentials of greenhouse gases emissions from the petrochemical industry, it is considered an alternative technology should be made efficiently for the actual workplace.

\section{Conclusion}

In this study, greenhouse gases emissions and reduction potentials were predicted using the LEAP model mainly for
TABLE-12

GHGS REDUCTION SCENARIO IN PETROCHEMICAL SECTOR (SCENARIO IV, 2005-2030); UNIT: THOUSAND $\mathrm{tCO}_{2} \mathrm{eq}$

\begin{tabular}{lcccc}
\hline & 2005 & 2013 & 2020 & 2030 \\
\hline Chemical and petro & 627.5 & 660.2 & 688.8 & 762.6 \\
Catalytic cracking & 627.5 & 659.8 & 688.0 & 761.6 \\
Methane cracking & 627.5 & 660.1 & 688.5 & 762.3 \\
Coking alloy & 627.5 & 659.9 & 688.3 & 762.3 \\
Metathesis & 627.5 & 659.9 & 688.2 & 762.3 \\
Dived wall calum & 627.5 & 660.1 & 688.5 & 762.3 \\
Butadien & 627.5 & 660.1 & 688.7 & 762.5 \\
Total & - & -1.3 & -2.6 & -2.3 \\
\hline
\end{tabular}

Seosan city's industrial sector that has a large consumption structure of energy. Energy consumption and greenhouse gases emissions were also predicted through the analysis of four scenarios resulting from the application of the reduction effect according to the basic energy plan and technology options of petrochemical industries. The main results obtained in this study can be summarized as follows:

- The energy consumption of Seosan city's industrial sector is predicted to be 1,353.3 thousand TOE as of 2030, an approximately 1.7 times increase compared to 2005. The annual average growth rate was expected to be $2.1 \%$ for the prediction period from 2005 to 2030 .

- After the analysis of the baseline (BAU) scenario, the energy consumption and greenhouse gases emissions were shown in the order of manufacturing $>$ construction $>$ agriculture, forestry and fisheries $>$ mining from the largest. In the case of manufacturing, the energy consumption accounted for $80.66 \%$ and greenhouse gases emissions, $51.07 \%$. The differences of the greenhouse gases calculation methodology according to the activity are considered as the biggest factor for the difference between the energy consumption and greenhouse gases emissions. In particular, greenhouse gases reduction measures are necessary for the petrochemical industry since it accounts for a high proportion of $86 \%$ out of the entire manufacturing industries.

- In Scenario I, the policy of the national basic energy plan was analyzed which showed an improvement of energy basic by an annual average of $2.6 \%$ until 2030 . Scenario I showed the effect of reducing greenhouse gases emissions of $18.23 \%$, 297.2 thousand $\mathrm{tCO}_{2}$; Scenario II, $14 \%$ in 2030 over 2005.

- It was analyzed that Scenario III showed a reduction of $8 \%, 135$ thousand $\mathrm{tCO}_{2}$ compared to the baseline scenario; Scenario IV showed a reduction of $0.2 \%$ in greenhouse gases emissions. Accordingly, based on the result of the $0.75 \%$ scenario which is commonly used as the annual average efficiency improvement rate of energy, the $30 \%$ reduction of greenhouse gases emissions was analyzed to be a difficult goal until 2020, the baseline of the response measures to climate change of Seosan city compared to 2005 emissions.

An emphasis was placed on the energy consumption survey in the industrial sector of Seosan city. The outlook for the greenhouse gases emissions based on the survey result; and building basic data for the reduction potential. The scenariobuilding may be insufficient because the data are undisclosed for the penetration rate of the greenhouse gases reduction technology. Still, the model established in this study is considered to have a higher utilization as the basic data in calculating 
the potential reductions for the future continuous establishment of energy policy and climate change response-related policies of Seosan city.

\section{ACKNOWLEDGEMENTS}

This work was supported by the Human Resources Development program (No. 20114010203130) of the Korea Institute of Energy Technology Evaluation and Planning (KETEP) grant funded by the Korea government Ministry of Trade, Industry and Energy.

\section{REFERENCES}

1. Korea Energy Economics Institute, Ministry of Commerce, Industry and Energy, Long-term Polices and Strategies on the United Nations Framework Convention of Climate Chang, KEEI Report (In Korean) (2004).

2. Y.Y. Kang. Study on Strategies to Address the United Nations Framework Convention on Climate Change and the Kyoto Protocol (the second year), Ministry of Commerce, Industry and Energy Report (In Korean) (2003).

3. K.S. Sim, A Study on Policy of Development for the Strategy of Korea according as the Climate Chang Convention. Dissertation, Chonnam Nation University (In Korean) (2005)
4. J.G. Oh, The GHG Mitigation Strategies and Role of Korea in the Post2012 Regime, Korea Energy Economics Institute (2009).

5. Climate Change Capital, After Kyoto Approaches to Climate Change Mitigation Post-2012 (2005).

6. J. Park, A Study on International Regime of United Nations Framework Convention on Climate Change-Focusing on the Fifteenth Conference on the Parties in Copenhagen, Dissertation, Sookmyung Women's University (In Korean) (2010).

7. H.J. Ann, The Role of Government and Industry in Confronting Global Warming, Dissertation, Kyungwon University (In Korean) (2008).

8. Y. Huang, Y.J. Bor and C.-Y. Peng, Energy Policy, 39, 6790 (2011).

9. H.C. Shin, J.W. Park, H.S. Kim and E.S. Shin, Energy Policy, 33, 1261 (2005).

10. R. Shabbir and S.S. Ahmad, Energy, 35, 2323 (2010).

11. J.H. Kim, A Study GHG Emissions and Reduction Potentials of the Industrial Sector in Daegu, Dissertation, Keimyung University, pp.4548 (2008)

12. IEA, Energy Technology Perspectives, p. 514 (2008).

13. IEA, Energy Technology Transition for Industry, p. 192 (2009).

14. Korea Energy Management Corporation, Investigate and Analysis on GHGs Reduce Option of Industrial Sector, pp. 52-53 (2003).

15. Korea Energy Management Corporation, Establishment of Energy Technology Database (2003). 